\title{
The association between senior student tobacco use rate at school and alternative tobacco product use among junior students in Canadian secondary schools
}

\author{
Adam G Cole ${ }^{*}$ and Scott T Leatherdale
}

\begin{abstract}
Background: The use of alternative tobacco products (ATPs) has grown in popularity among Canadian youth. This study examined the association between a school-level characteristic (the senior student tobacco use rate) and the current use of manufactured cigarettes, little cigars or cigarillos, cigars, roll-your-own cigarettes, smokeless tobacco (SLT), and a hookah among junior students.

Methods: This study used nationally representative Canadian data from 29,495 students in grades 9 to 12 as part of the 2010/2011 Youth Smoking Survey. For each ATP, we described rates of senior and junior tobacco use, calculated the variance attributed to school-level factors, and examined the association between the senior student (grades 11 and 12) tobacco use rate and the current use of each ATP among junior students (grades 9 and 10) while accounting for relevant student-level characteristics. SAS 9.3 was used for all analyses.

Results: Over half of schools sampled had senior students that reported using each ATP. School-level differences accounted for between $14.1 \%$ and $29.7 \%$ of the variability in ATP current use among junior students. Each one percent increase in the number of senior students at a school that currently use manufactured cigarettes, SLT, or a hookah was significantly independently associated with an increased likelihood that a junior student at that school currently used manufactured cigarettes (OR 1.04, 95\% Cl 1.01 to 1.06), SLT (OR 1.14, 95\% Cl 1.06 to 1.24), or a hookah (OR 1.09, 95\% Cl 1.03 to 1.14$)$.

Conclusions: Characteristics of the school environment a junior student attends appear to play an important role in ATP use, and tobacco control programs and policies should be designed to ensure that they include strategies to curb the use of all tobacco products. Additional evidence is needed for the impact of comprehensive school-based tobacco control approaches.
\end{abstract}

Keywords: Tobacco products, Adolescent, Tobacco use

\section{Background}

Over the past decade, the use of manufactured cigarettes among Canadian youth has decreased substantially [1]; however, evidence suggests that the use of alternative tobacco products (ATPs) such as roll-your-own tobacco, small cigars, and moist snuff has increased [2]. Because of the lower cost and appealing flavours of many of these products $[3,4]$, youth may be enticed to try ATPs

\footnotetext{
* Correspondence: agcole@uwaterloo.ca

School of Public Health and Health Systems, University of Waterloo, 200 University Avenue, Waterloo, ON N2L 3G1, Canada
}

despite the health risks [5-8]. In addition, public health programs and policies that specifically address the prevention of use of ATPs are lacking (e.g., the Ontario Tobacco Control Strategy [9]). Given that there is little evidence identifying the factors associated with youth using ATPs, this is a domain that requires additional investigation.

Existing evidence indicates that youth who use ATPs and youth who use manufactured cigarettes share many characteristics, such as being male, older, and having more disposable income [10-12]. Furthermore, studies 
suggest that youth who use one tobacco product are more likely to use additional tobacco products [10-12]. Given that existing research indicates that junior students who attend schools with a higher prevalence of senior students that smoke manufactured cigarettes are more likely to smoke manufactured cigarettes [13], it is possible that a similar relationship may exist for ATPs. For instance, it would be informative to identify if junior students attending a school with a higher prevalence of senior students who use smokeless tobacco are more likely to use smokeless tobacco themselves. Confirming the presence of such an association would have important ramifications for targeting school-level prevention interventions given that youth spend a considerable amount of time at school where they can be influenced by tobacco control programming [13-16]. Moreover, considering that international data illustrate that comprehensive school-based tobacco control programs that prohibit the use of various tobacco products on school property have had a positive influence on the use of smokeless tobacco and manufactured cigarettes [17], this is a domain that warrants investigation in the Canadian context.

Therefore, the purpose of this study was to examine the association between a school-level characteristic (the senior student tobacco use rate) to the current use of five ATPs (little cigars or cigarillos, cigars, roll-your-own (RYO) cigarettes, smokeless tobacco (SLT), and hookah) among junior students in a nationally representative sample of secondary schools in Canada. Specifically, this study described the prevalence of senior students (grade 11 and 12) and junior students (grade 9 and 10) that use each ATP, calculated the variance in junior tobacco use rates that was attributable to school-level characteristics, and examined the association between the senior student tobacco use rate and the current use of ATPs among junior students while accounting for relevant student-level characteristics.

\section{Methods}

\section{Sampling and recruitment}

This cross-sectional study used representative data collected from 15,038 students in grades 9 and 10 and 14,457 students in grades 11 and 12 as part of the 2010/ 2011 cycle of the Canadian Youth Smoking Survey (YSS). The YSS is a self-reported questionnaire that students complete during class time; participants were not provided compensation. As described elsewhere [18], the target population for the data consisted of all young Canadian residents in grades 9 to 12 attending public, private, and Catholic secondary schools in 9 Canadian provinces. While New Brunswick participated in all prior cycles of the YSS, the provincial government chose not to participate in $2010 / 2011$. Additionally, youth residing in Yukon, Nunavut, and the Northwest Territories were excluded from the target population, as were youth living in institutions or on First Nation Reserves and youth attending special schools or schools on military bases. The survey design and sample weight allow us to produce the population-based estimates within this manuscript. The University of Waterloo Office of Research Ethics and appropriate School Board and Public Health Ethics committees approved all procedures, including passive consent.

\section{Tobacco use}

Current smoking status was measured by asking respondents if they have ever smoked 100 or more whole cigarettes in their lifetime, and on how many of the last 30 days they smoked one or more cigarettes. Consistent with Health Canada's definitions of smoking status for the YSS [18] and the available measure of ATP use described below, current manufactured cigarette smokers had smoked at least one whole cigarette during the last 30 days preceding the survey. All other respondents were classified as non-smokers.

ATP use was measured using one multi-item question on alternate tobacco use. This question measured current use of each ATP among respondents: "In the last 30 days, did you use any of the following? (Mark all that apply)", followed by a list of forms of tobacco other than cigarettes: cigarillos or little cigars (plain or flavoured), cigars (not including cigarillos or little cigars, plain or flavoured), roll-your-own cigarettes (tobacco only), smokeless tobacco (chewing tobacco, pinch, snuff, or snus), and water-pipe to smoke tobacco (also known as a hookah, sheesha, narg-eelay, hubble-bubble, or gouza). For this analysis, any respondents with all items missing had ATP current use set to missing.

\section{Student-level characteristics}

The YSS also collected information on demographics, weekly spending money, and alcohol and marijuana use, which are important predictors of tobacco use. Similar to previous definitions $[19,20]$, non-drinkers did not report alcohol use in the last year, occasional drinkers reported monthly alcohol use, and current drinkers reported weekly alcohol use. Similarly, non-marijuana users did not report marijuana use in the last year, occasional marijuana users reported monthly marijuana use, and current marijuana users reported weekly marijuana use.

\section{Senior student tobacco use rate}

The senior student manufactured cigarette smoking rate for each school was calculated based on the number of current manufactured cigarette smokers in grades 11 and 12 (senior students) in the school, divided by the 
total number of senior students in the school. Similarly, the senior student little cigar or cigarillo, cigar, RYO cigarette, SLT, and hookah use rates for each school were calculated in a similar manner. In Quebec, the maximum grade in secondary school is grade 11; therefore, only grade 11 students were considered senior students in Quebec. All regression analyses only included grades 9 and 10 students (junior students) in the predictive models.

Schools were also classified as rural, suburban, or urban according to the population and population density obtained from the Statistics Canada website using the school's postal code.

\section{Data analysis}

Survey weights were used in the descriptive statistics of student-level characteristics to adjust for differential response rates across regions or groups. As described previously [18], the development of the survey weight was accomplished in two stages. In the first stage a weight $\left(\mathrm{W}_{1 \mathrm{j}}\right)$ was created to account for the school selection within health region and school strata. A second weight $\left(\mathrm{W}_{2 \mathrm{jg}}\right)$ was calculated to adjust for student non-response. The weights were then calibrated to the provincial gender and grade distribution so that the total of the survey weights by gender, grade and province would equal the actual enrolments in those groups.

Weighted descriptive analyses of the sample characteristics among junior students were examined according to tobacco product. The overall mean and range of senior student tobacco use rates were calculated, and unweighted analysis of variance statistics tested for significant differences in senior student tobacco use rates according to region and geographic classification. We then conducted two multilevel regression models per tobacco product among junior students using PROC GLIMMIX in SAS. The first model examined whether ATP use varied across schools through calculation of the intraclass correlation coefficient. The second model examined whether the senior student tobacco use rate was associated with the current use of each ATP while controlling for region, geographic classification, and various student-level characteristics. All analyses were performed using SAS 9.3 [21].

\section{Results}

\section{Sample characteristics}

Table 1 provides a summary of the number of included students by gender, grade, and region. Overall, there were no significant gender or grade differences in the number of junior students $\left(x^{2}=1.19, \mathrm{df}=1, \mathrm{p}>0.05\right)$. Similarly, there were no significant gender or grade differences in the number of senior students $\left(x^{2}=1.59\right.$, $\mathrm{df}=1, \mathrm{p}>0.05$ ).

\section{Descriptive statistics for senior student tobacco use rates}

As shown in Table 2, over half of schools sampled had senior students that reported currently using each product. The mean school senior student tobacco use rate varied across products: $5.5 \%( \pm 4.0)$ of senior students within a school reported currently using a hookah, while $15.6 \%( \pm 11.0)$ of senior students within a school reported currently using manufactured cigarettes. Figure 1 illustrates the mean senior student tobacco use rates across region. Overall, the mean senior student manufactured cigarette rate $(\mathrm{F}(4,133)=6.40, \mathrm{p}<0.001)$, little

Table 1 Summary of unweighted sample characteristics, 2010-2011, Canada

\begin{tabular}{|c|c|c|c|c|c|}
\hline \multirow{2}{*}{ Region } & \multirow{2}{*}{ Gender } & \multicolumn{4}{|c|}{ Grade, n (\%) } \\
\hline & & 9 & 10 & 11 & 12 \\
\hline \multirow{2}{*}{ Atlantic ${ }^{a}$} & Male & $338(4.4)$ & 1181 (15.3) & $1162(15.1)$ & 1060 (13.8) \\
\hline & Female & $381(5.0)$ & $1263(16.4)$ & $1243(16.2)$ & $1070(13.9)$ \\
\hline \multirow{2}{*}{ Quebec $^{b}$} & Male & $277(18.4)$ & $223(14.9)$ & $240(16.0)$ & $\mathrm{n} / \mathrm{a}$ \\
\hline & Female & $292(19.4)$ & $233(15.5)$ & $237(15.8)$ & $\mathrm{n} / \mathrm{a}$ \\
\hline \multirow{2}{*}{ Ontario } & Male & $894(14.1)$ & 767 (12.1) & $730(11.5)$ & 665 (10.5) \\
\hline & Female & $956(15.0)$ & 881 (13.9) & $793(12.5)$ & $670(10.5)$ \\
\hline \multirow{2}{*}{ Prairies $^{c}$} & Male & 1034 (11.6) & $1367(15.4)$ & $1174(13.2)$ & $943(10.6)$ \\
\hline & Female & $910(10.3)$ & 1365 (15.4) & $1160(13.1)$ & 929 (10.5) \\
\hline \multirow{2}{*}{ British Columbia } & Male & $680(13.5)$ & 753 (14.9) & $667(13.2)$ & $586(11.6)$ \\
\hline & Female & $622(12.3)$ & $621(12.3)$ & $617(12.2)$ & $511(10.1)$ \\
\hline \multirow{2}{*}{ TOTAL } & Male & $3223(10.9)$ & 4291 (14.6) & $3973(13.5)$ & $3254(11.0)$ \\
\hline & Female & $3161(10.7)$ & $4363(14.8)$ & $4050(13.7)$ & $3180(10.8)$ \\
\hline
\end{tabular}

Note: Data derived from the 2010-2011 National Youth Smoking Survey.

${ }^{a}$ Atlantic region includes Newfoundland and Labrador, Prince Edward Island and Nova Scotia.

${ }^{b}$ In Quebec, the maximum grade in secondary school is grade 11.

'Prairie region includes Manitoba, Saskatchewan and Alberta. 
Table 2 Summary of school-level senior student (grades 11 and 12) tobacco use rates, 2010-2011, Canada

\begin{tabular}{|c|c|c|c|c|}
\hline \multirow{2}{*}{ Tobacco product } & \multirow{2}{*}{$\begin{array}{l}\text { Percent of schools with } \\
\text { senior current users }\end{array}$} & \multicolumn{3}{|c|}{ Senior student tobacco use rate $(\%)^{\mathbf{b}}$} \\
\hline & & Mean (Std. Dev.) & Minimum & Maximum \\
\hline Manufactured cigarettes & 91.3 & $15.6( \pm 11.0)$ & 1.9 & 100.0 \\
\hline Little cigars or cigarillos & 89.9 & $11.7( \pm 6.9)$ & 1.7 & 33.3 \\
\hline Cigars & 79.0 & $9.7( \pm 10.5)$ & 1.0 & 100.0 \\
\hline Roll-your-own cigarettes & 76.1 & $7.1( \pm 4.5)$ & 0.5 & 20.4 \\
\hline Smokeless tobacco & 60.1 & $5.9( \pm 5.0)$ & 0.2 & 27.3 \\
\hline Hookah & 66.7 & $5.5( \pm 4.0)$ & 0.7 & 28.6 \\
\hline
\end{tabular}

Note: Data derived from the 2010-2011 National Youth Smoking Survey.

${ }^{\mathrm{a}} 138$ schools were identified with senior students (grades 11 or 12). Current manufactured cigarette users had smoked at least 100 cigarettes in their lifetime and smoked at least one whole cigarette during the past 30 days; all other current tobacco users had used the respective tobacco product at least once during the past 30 days.

${ }^{\mathrm{b}}$ Excludes schools with no senior current users.

cigar or cigarillo rate $(\mathrm{F}(4,133)=2.93, \mathrm{p}<0.05)$, cigar rate $(\mathrm{F}(4,133)=2.80, \mathrm{p}<0.05), \mathrm{RYO}$ cigarette rate $(\mathrm{F}(4,133)=$ 8.43, $\mathrm{p}<0.001)$, and SLT rate $(\mathrm{F}(4,133)=10.32, \mathrm{p}<0.001)$ differed significantly across region.

\section{Descriptive statistics for current tobacco product use among junior students}

Overall, 10.9\% of Canadian junior students reported currently using manufactured cigarettes. As shown in Table 3, there were no significant gender differences in the use of manufactured cigarettes among junior students $\left(x^{2}=2.50, \mathrm{df}=1, \mathrm{p}>0.05\right)$, but more junior students in grade 10 reported currently using manufactured cigarettes compared to junior students in grade $9\left(x^{2}=\right.$ 32.27, $\mathrm{df}=1, \mathrm{p}<0.001)$. An estimated $5.9 \%$ of Canadian junior students reported currently using little cigars or cigarillos and $4.1 \%$ reported currently using cigars. As shown in Table 3, more male junior students reported currently using little cigars or cigarillos, and cigars compared to female junior students $\left(\mathrm{x}^{2}=83.4, \mathrm{df}=1, \mathrm{p}<0.001\right.$; and

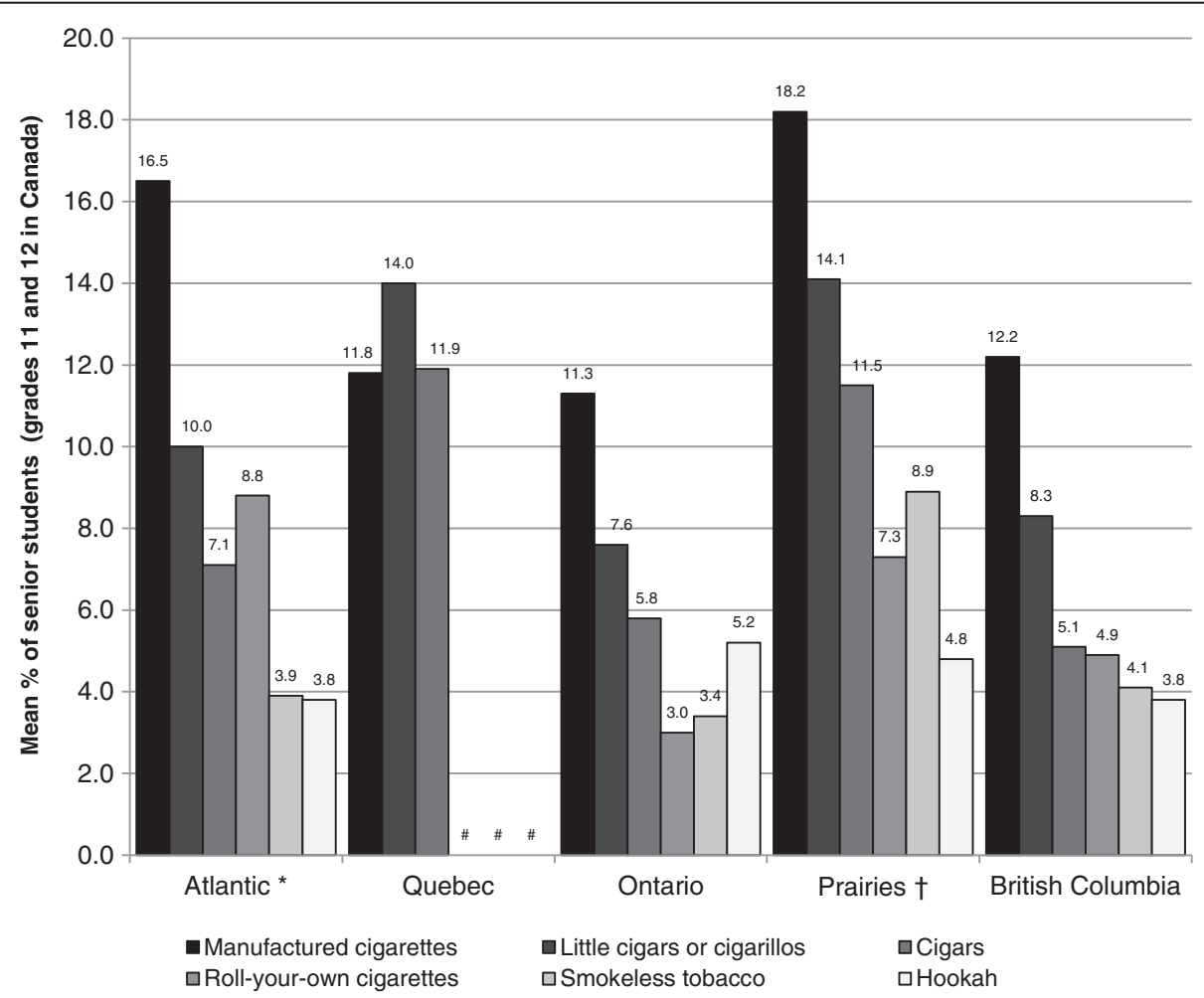

Figure 1 Mean senior student (grade 11 and 12) tobacco use rate in secondary schools, by region, 2010-11, Canada. Note: Data derived from the 2010-2011 National Youth Smoking Survey. * Atlantic region includes Newfoundland and Labrador, Prince Edward Island and Nova Scotia. † Prairie region includes Manitoba, Saskatchewan and Alberta. \# Data suppressed due to high sampling variability. 
Table 3 Weighted percent of current tobacco product use by demographic variables among junior students (grades 9 and 10), 2010-2011, Canada

\begin{tabular}{|c|c|c|c|c|c|c|c|}
\hline \multirow{2}{*}{\multicolumn{2}{|c|}{ Parameters }} & Manufactured cigarettes & Little cigars or cigarillos & Cigars & Roll-your-own cigarettes & Smokeless tobacco & Hookah \\
\hline & & \multicolumn{6}{|c|}{$\%$ of students } \\
\hline \multirow[t]{2}{*}{ Gender } & Female & 10.5 & 4.0 & 2.6 & 2.4 & 0.7 & 1.7 \\
\hline & Male & 11.3 & 7.6 & 5.5 & 4.2 & 2.6 & 3.2 \\
\hline \multirow[t]{2}{*}{ Grade } & 9 & 9.4 & 4.9 & 3.6 & 2.8 & 1.3 & 1.8 \\
\hline & 10 & 12.3 & 6.7 & 4.5 & 3.9 & 2.0 & 3.0 \\
\hline
\end{tabular}

Note: Data derived from the 2010-2011 National Youth Smoking Survey.

$\mathrm{X}^{2}=81.2, \mathrm{df}=1, \mathrm{p}<0.001$, respectively), and more junior students in grade 10 reported currently using little cigars or cigarillos, and cigars compared to junior students in grade $9\left(\chi^{2}=19.1, \mathrm{df}=1, \mathrm{p}<0.001\right.$; and $\mathrm{X}^{2}=6.6, \mathrm{df}=1$, $\mathrm{p}<0.05$, respectively). Additionally, $3.4 \%$ of Canadian junior students reported currently using RYO cigarettes, $1.7 \%$ reported currently using SLT, and $2.5 \%$ reported currently using a hookah. As shown in Table 3, more male junior students reported currently using RYO cigarettes, SLT, and hookah compared to female junior students $\left(\chi^{2}=\right.$ 34.8, $\mathrm{df}=1, \mathrm{p}<0.001 ; \mathrm{X}^{2}=83.7, \mathrm{df}=1, \mathrm{p}<0.001$; and $\chi^{2}=$
33.3, $\mathrm{df}=1, \mathrm{p}<0.001$, respectively), and more junior students in grade 10 reported currently using RYO cigarettes, SLT, and a hookah compared to junior students in grade 9 $\left(\chi^{2}=13.2, \mathrm{df}=1, \mathrm{p}<0.001 ; \chi^{2}=11.8, \mathrm{df}=1, \mathrm{p}<0.001\right.$; and $\chi^{2}=20.9, \mathrm{df}=1, \mathrm{p}<0.001$, respectively).

Figure 2 compares the prevalence of current use of each tobacco product among junior students in Canada by region. Compared to manufactured cigarettes, the use of other tobacco products is lower across all regions among junior students. The current use of little cigars or cigarillos is highest among junior students in Quebec

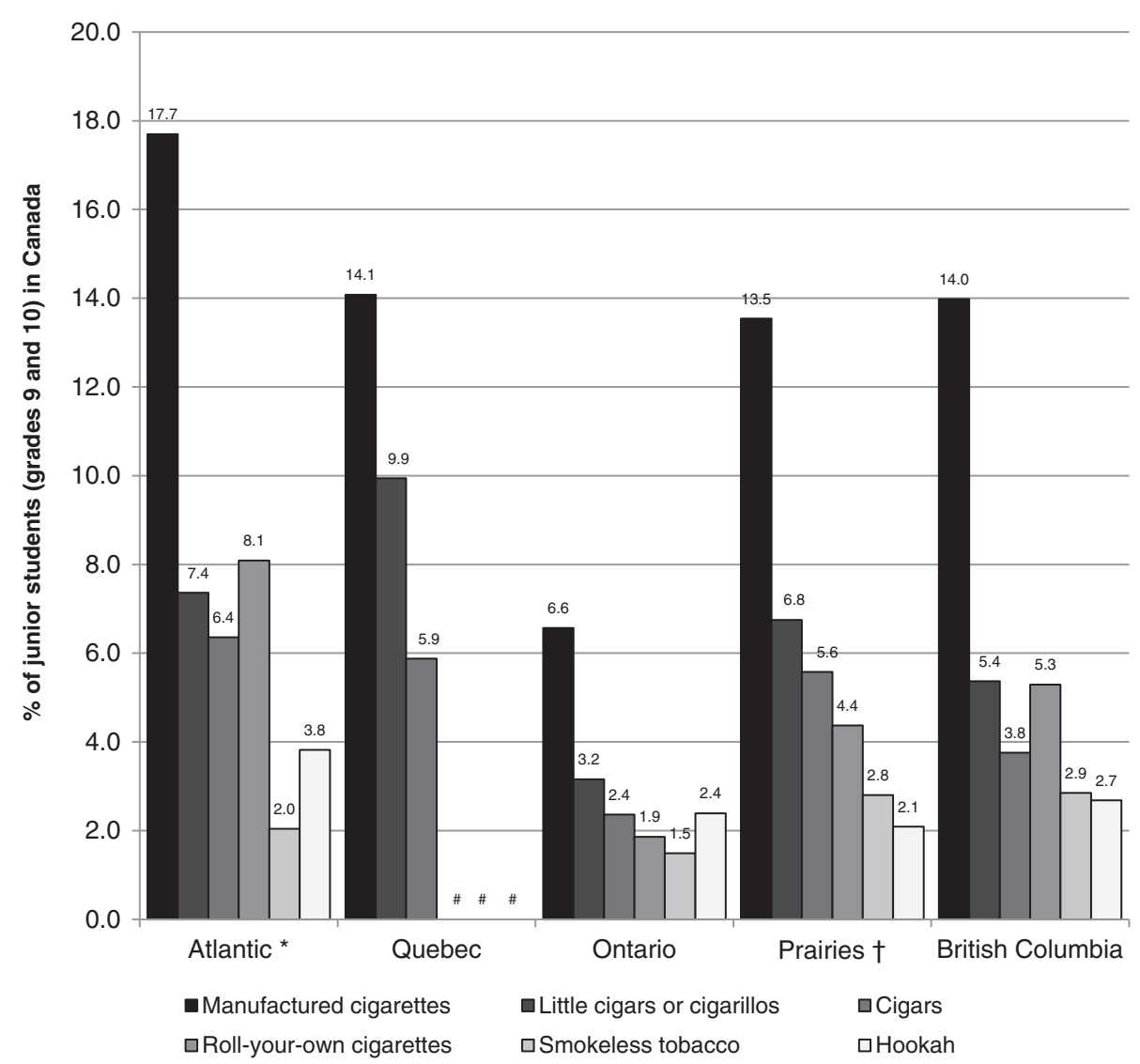

Figure 2 Prevalence of current tobacco product use among Canadian students in grades 9 and 10, by region, 2010-11, Canada. Note: Data derived from the 2010-2011 National Youth Smoking Survey. ${ }^{*}$ Atlantic region includes Newfoundland and Labrador, Prince Edward Island and Nova Scotia. † Prairie region includes Manitoba, Saskatchewan and Alberta. \# Data suppressed due to high sampling variability. 
(9.9\%) and lowest in Ontario (3.2\%), while the current use of SLT is highest among junior students in British Columbia (2.9\%) and lowest in Ontario (1.5\%). Additionally, the current use of cigars and RYO cigarettes is highest among junior students in the Atlantic region (6.4\% and $8.1 \%$, respectively) and lowest in Ontario $(2.4 \%$ and $1.9 \%$, respectively), while the current use of a hookah is highest among junior students in the Atlantic region (3.8\%) and lowest in the Prairie region (2.1\%).

\section{Between school variability in ATP use}

Among Canadian junior students, significant betweenschool random variation in the odds of being a current little cigar or cigarillo, cigar, RYO cigarette, SLT, or hookah user were identified. As shown in Table 4, schoollevel differences accounted for between 14.1\% and 29.7\% of the variability in ATP current use among junior students.

Multilevel regression model results for the association between the senior student tobacco use rate and current ATP use among junior students

Table 5 presents a summary of the relative odds ratio estimates and corresponding p-values of current ATP use among junior students for each one percent increase in the number of senior students that currently use an ATP, controlling for region, geographic classification, and relevant student-level characteristics. It was identified that a one percent increase in the number of senior students at a school that currently use manufactured cigarettes was significantly associated with an increased likelihood that a junior student at that school currently used manufactured cigarettes (OR 1.04, 95\% CI 1.01 to 1.06); a one percent increase in the number of senior students at a school that currently use SLT was also significantly associated with an increased likelihood that a junior student at that school currently used SLT (OR $1.14,95 \%$ CI 1.06 to 1.24$)$. Finally, a one percent increase in the number of senior students at a school that currently use a hookah was significantly associated with an increased likelihood that a junior student at that school

Table 4 Intraclass correlation coefficients for current use of various alternative tobacco products among junior students (grades 9 and 10), 2010-2011, Canada

\begin{tabular}{lcc}
\hline Alternative tobacco product & $\mathbf{\sigma}^{\mathbf{2}} \boldsymbol{\mu \mathbf { 0 }}^{\mathbf{a}}$ & $\begin{array}{c}\text { Intraclass correlation } \\
\text { coefficient }\end{array}$ \\
\hline Cigarillos or little cigars & $0.613(0.116)$ & 0.157 \\
Cigars & $0.540(0.118)$ & 0.141 \\
Roll-your-own cigarettes & $0.945(0.192)$ & 0.223 \\
Smokeless tobacco & $1.391(0.318)$ & 0.297 \\
Hookah & $0.659(0.157)$ & 0.167 \\
\hline
\end{tabular}

Note: Data derived from the 2010-2011 National Youth Smoking Survey. ${ }^{\mathrm{a}}$ All models based on data from 138 secondary schools.
Table 5 Summary of relative odds ratios of current tobacco use among junior students (grades 9 and 10) for each percent increase in the number of senior students that use each tobacco product, 2010-2011, Canada

\begin{tabular}{lcc}
\hline Tobacco product & ${\text { Relative odds ratio }(\mathbf{9 5} \% \mathrm{Cl})^{\mathrm{a}}}^{\mathrm{a}}$ & $\mathbf{p}$-value \\
\hline Manufactured cigarettes & $1.04(1.01,1.06)$ & 0.002 \\
Little cigars or cigarillos & $1.01(0.98,1.04)$ & 0.526 \\
Cigars & $1.01(0.97,1.05)$ & 0.656 \\
Roll-your-own cigarettes & $1.03(0.95,1.11)$ & 0.491 \\
Smokeless tobacco & $1.14(1.06,1.24)$ & $<0.001$ \\
Hookah & $1.09(1.03,1.14)$ & 0.003 \\
\hline
\end{tabular}

Note: Data derived from the 2010-2011 National Youth Smoking Survey. ${ }^{a}$ All models based on data from 133 secondary schools, controlling for region, geographic classification, and student-level characteristics (gender, grade, ethnicity, smoking status, parental smoking status, sibling smoking status, friend smoking status, disposable income, drinking status, and marijuana use status).

currently used a hookah (OR 1.09, 95\% CI 1.03 to 1.14). Although not statistically significant, each percent increase in the number of senior students at a school that currently use little cigars or cigarillos, cigars, or RYO cigarettes also modestly increased the likelihood that a junior student at that school currently used each of these products respectively. Figure 3 graphically illustrates the model-based estimated odds ratios of current tobacco product use among junior students for every percent increase in the prevalence of senior students at a school that currently use an ATP. For example, this figure illustrates that junior students that attend a school with an average senior student SLT use rate $(5.9 \%)$ are almost twice as likely to currently use SLT compared to students that attend a school with no senior students that currently use SLT. In contrast, junior students that attend a school with the maximum senior student SLT use rate in this sample (27.3\%) are almost five times as likely to currently use SLT compared to students that attend a school with no senior students that currently use SLT.

\section{Discussion}

Alternative tobacco product (ATP) use is an important tobacco control issue among Canadian youth, and our results support the importance of the school environment to tobacco control initiatives. These data indicate that factors within the school environment accounted for up to $29 \%$ of the variability in ATP current use among junior students. The traditional research focus primarily on manufactured cigarettes has left a gap in our understanding where relatively little is known with respect to school-level factors that influence the use of ATPs, especially among youth. As a result, many current school-based tobacco control policies focus on the use of manufactured cigarettes and do not address the use of ATPs despite the known health risks. The lack of 


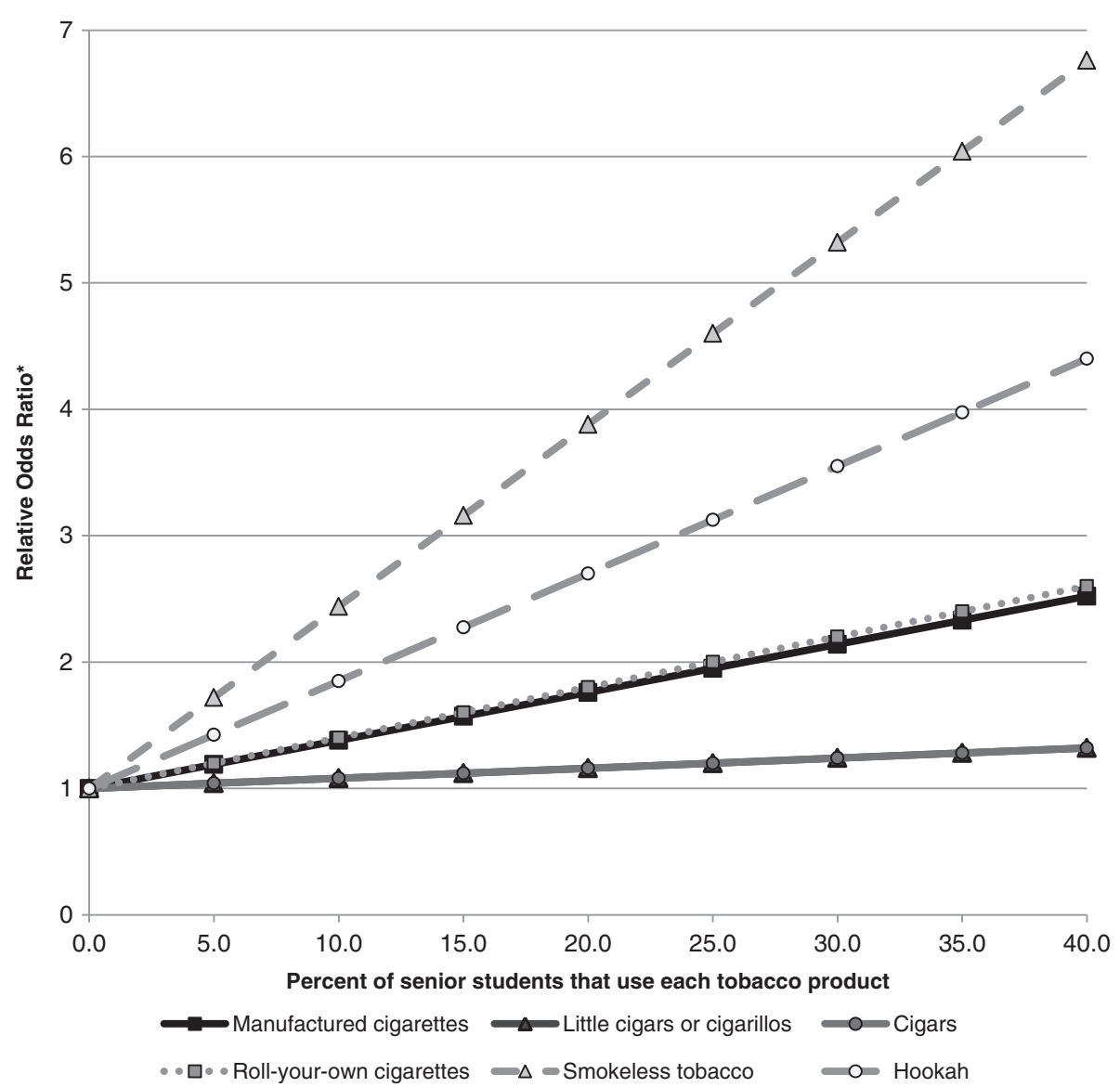

Figure 3 Summary of relative odds ratios of current tobacco use with each percent increase in the number of senior students that use each tobacco product, controlling for region, geographic classification, and relevant student-level characteristics*, 2010-11, Canada. Note: Data derived from the 2010-2011 National Youth Smoking Survey. * All models based on data from 133 secondary schools, controlling for region, geographic classification, and student-level characteristics (gender, grade, ethnicity, smoking status, parental smoking status, sibling smoking status, friend smoking status, disposable income, drinking status, and marijuana use status).

school-based policies that address the use of ATPs may be contributing to high rates of use, as our data illustrate that the majority of schools have senior students that use at least one tobacco product, and rates of tobacco use among senior students within a secondary school reach as high as $100 \%$. It is clear that additional efforts are required to ensure that current and future tobacco control policies are not focused on a single product, but rather are designed to prevent the use of the broad range of tobacco products currently available in the marketplace. For example, the Smoke-Free Ontario Act, which prohibits smoking or holding lit tobacco at schools, could be amended to prohibit the use unlit tobacco products (such as SLT) at school [22].

These data provide additional support for the influence of older students to tobacco use among junior students. Figures 1 and 2 suggest that rates of tobacco use among senior students are mirrored among junior students: regions with high rates of tobacco use among senior students also have high rates of tobacco use among junior students. In fact, the results of the multilevel regression analyses show that high rates of SLT use and hookah use among senior students are independently associated with an increased likelihood that a junior student currently uses each of these products. This was especially true for SLT where a grade 9 or $10 \mathrm{stu}$ dent was approximately 5 times more likely to currently use SLT when at least $27 \%$ of senior students currently used SLT (the maximum senior student use rate in this sample). Since peers influence tobacco use $[23,24]$ and students obtain tobacco products from each other $[25,26]$, students may be exposed to non-traditional tobacco products through older students at the school. This has important implications for current and future school-based tobacco control policies. It is evident that inclusive tobacco control policies are necessary to ensure that students are not exposed to novel tobacco products through social influences in the school environment. 
Numerous reasons have been identified to explain how a higher prevalence of senior student manufactured cigarette use influences junior student manufactured cigarette use, namely by increasing the acceptability of smoking behaviours $[27,28]$, by increasing the availability of manufactured cigarettes at school [26,29], and by increasing the likelihood that a student has a friend that smokes manufactured cigarettes [30,31]. It is possible that senior students that use SLT or a hookah may influence junior students through a similar mechanism; however, future studies should explore the relationship between senior and junior tobacco users in order to inform future school-based tobacco control policies. Since there is evidence that school policies that prohibit the use of snus by students during school hours reduce the likelihood that a student uses snus [32], initiatives such as the Smoke-Free Ontario Act should be amended to prohibit the use of all tobacco products on and around school property, not just combustible products. In this way, the use of all tobacco products, including SLT, would be included in current tobacco control policies within the school context. The impact of this more comprehensive tobacco control approach would require evaluation.

Given the wide range of senior student tobacco use rates identified in this study (e.g., between 0\% and 33\% of senior students smoke little cigars or cigarillos in secondary schools), additional evidence is required to evaluate whether there are school policies in effect for the use of ATPs, whether these policies are consistently implemented and enforced, and what effect these policies have on the use of ATPs among students. Knowledge of these school policies will inform whether new school-based prevention and cessation programs are necessary or whether current school-based programs can be expanded to include the use of ATPs. Consequently, school-based policy evaluation tools (such as COMPASS; www.compass.uwaterloo.ca) that include questions that evaluate the existence and implementation of schoolbased programs and policies that aim to prevent the use of ATPs, represent an important domain of future research. Moreover, there may be a substantial benefit to future tobacco control prevention programming if researchers develop measures to identify the youth who are susceptible to using ATPs or multiple tobacco products, similar to the smoking susceptibility measure for manufactured cigarettes [33]. Measures of ATP susceptibility would allow researchers and practitioners to screen for youth who would be at the highest future risk for using ATPs and who should benefit the most from school-based ATP interventions.

The use of secondary data in this study presents a few limitations. Firstly, the current study relies on selfreported smoking behaviours; therefore the validity of responses cannot be guaranteed. However, self-report tobacco use measures have previously been demonstrated to be reliable and valid [34] and students were ensured that their responses were confidential. Secondly, measures of current use of tobacco products may not represent the usual use of these products by respondents and they do not provide any indication of the frequency of use. It is possible that a respondent first used a product once within the last 30 days; therefore this respondent would be classified as a current user, even though they are not a regular tobacco user. Thirdly, the crosssectional nature of the data do not allow for the examination of how changes in the senior student smoking rates influence ATP use. Finally, it was outside of the scope of the current study to include school-level policy information which could impact senior student tobacco use rates. As a result, the relationship between schoollevel policies and the use of ATPs cannot be evaluated.

Despite these limitations, the present study has several strengths. First, the YSS is a nationally representative survey, providing insight to provincial differences in tobacco product use in Canada. Additionally, the YSS collects data on a range of tobacco products, producing the most comprehensive picture of tobacco use among youth in Canada. Moreover, this research expands on limited data for the influence of school-level characteristics to the use of ATPs. Finally, this research is the first to examine the influence of senior student tobacco use rates to the use of various ATPs.

\section{Conclusions}

Tobacco use continues to be one of the most preventable causes of death and disability despite many public health programs and policies that discourage use. These data illustrate that characteristics of the school environment a student attends, such as the senior student tobacco use rate, appear to play an important role in ATP use among younger students in grades 9 and 10. Given the general positive association between the number of senior students that use ATPs and the likelihood that a junior student uses an ATP, additional evidence is required to examine the role of the school environment to the initiation and escalation of ATP use.

\section{Abbreviations}

ATP: Alternative tobacco product; RYO cigarettes: Roll-your-own cigarettes; SLT: Smokeless tobacco.

\section{Competing interests}

Both authors declare that they have no competing interest.

\section{Authors' contributions}

Both authors participated in the design of the study, analysis of the results, and helped to draft the manuscript. AC performed the statistical analysis. Both authors read and approved the final manuscript. 


\section{Acknowledgements}

The Youth Smoking Survey is a product of the pan-Canadian capacity building project funded through a contribution agreement between Health Canada and the Propel Centre for Population Health Impact at the University of Waterloo. This pan-Canadian consortium included Canadian tobacco control researchers from all provinces and provided training opportunities for university students at all levels, encouraging their involvement and growth in the field of tobacco control research.

Production of this paper has been made possible through a financial contribution from the Ontario Tobacco Research Unit.

Received: 2 April 2014 Accepted: 25 April 2014

Published: 1 May 2014

\section{References}

1. Reid JL, Hammond D, Rynard VL, Burkhalter R: Tobacco Use in Canada: Patterns and Trends, 2014 Edition. Waterloo, ON: Propel Centre for Population Health Impact, University of Waterloo; 2014.

2. Connolly GN, Alpert HR: Trends in the use of cigarettes and other tobacco products, 2000-2007. JAMA 2008, 299:2629-2630.

3. Richter P, Caraballo R, Gupta N, Pederson LL: Exploring use of nontraditional tobacco products through focus groups with young adult smokers, 2002. Prev Chronic Dis 2008, 5(3):1-8.

4. Soldz A, Dorsey E: Youth attitudes and beliefs toward alternative tobacco products: cigars, bidis, and kreteks. Health Educ Behav 2005, 32:549-566. doi:10.1177/1090198105276219.

5. Akl EA, Gaddam S, Gunukula SK, Honeine R, Jaoude PA, Irani J: The effects of waterpipe tobacco smoking on health outcomes: a systematic review. Int J Epidemiol 2010, 39:834-857. doi:10.1093/ije/dyq002.

6. Engeland A, Haldorsen T, Andersen A, Tretli S: The impact of smoking habits on lung cancer risk: 28 years' observation of 26,000 Norwegian men and women. Cancer Causes Control 1996, 7:366-376.

7. Iribarren C, Tekawa IS, Sidney S, Friedman GD: Effect of cigar smoking on the risk of cardiovascular disease, chronic obstructive pulmonary disease, and cancer in men. N Engl J Med 1999, 340(23):1773-1780.

8. Rodu B, Jansson C: Smokeless tobacco and oral cancer: a review of the risks and determinants. Crit Rev Oral Biol Med 2004, 15(5):252-263. doi:10.1177/154411130401500502.

9. Tobacco Strategy Advisory Group: Building on our gains, taking action now: Ontario's Tobacco Control Strategy for 2011-2016. http://www.mhp. gov.on.ca/en/smoke-free/TSAG\%20Report.pdf.

10. Czoli CD, Leatherdale ST, Rynard V: Bidi and Hookah use among Canadian youth: findings from the 2010 Canadian youth smoking survey. Prev Chronic Dis 2013, 10:120290. http://dx.doi.org/10.5888/pcd10.120290.

11. Leatherdale ST, Rios P, Elton-Marshall T, Burkhalter R: Cigar, cigarillo, and little cigar use among Canadian youth: are we underestimating the magnitude of this problem? J Prim Prev 2011, 32:161-170. doi:10.1007/ s10935-011-0248-6.

12. Loukas A, Batanova MD, Velazquez CE, Lang WJ, Sneden GG, Pasch KE, Karn SS, Robertson TR: Who uses snus? A study of Texas adolescents. Nicotine Tob Res 2012, 14(5):626-630.

13. Murnaghan DA, Leatherdale ST, Sihvonen M, Kekki P: A multilevel analysis examining the association between school-based smoking policies, prevention programs and youth smoking behavior: evaluating a provincial tobacco control strategy. Health Educ Res 2008, 23(6):1016-1028.

14. Baillie LE, Lovato CY, Taylor E, Rutherford MB, Smith M: The pit and the pendulum: the impact on teen smokers of including a designated smoking area in school tobacco control policy. Health Educ Res 2008, 23(6):1008-1015

15. Leatherdale ST, McDonald PW, Jolin M, Cameron R, Brown KS: A multi-level analysis examining how smoking friends, parents, and older students in the school environment are risk factors for susceptibility to smoking among non-smoking elementary school youth. Prev Sci 2006, 7(4):397-402.

16. Lovato CY, Zeisser C, Campbell S, Watts AW, Halpin P, Thompson M, Eyles J, Adlaf E, Brown S: Adolescent smoking: Effect of school and community characteristics. Am J Prev Med 2010, 39(6):507-514.

17. Sinha DN, Gupta PC, Warren CW, Asma S: School policy and tobacco use by students in Bihar, India. Indian J Public Health 2004, 48(3):118-122.

18. Elton-Marshall T, Leatherdale ST, Manske SR, Wong K, Ahmed R, Burkhalter R: Research Methods of the Youth Smoking Survey (YSS). Chronic Dis Inj Can 2011, 32:47-54.
19. Leatherdale ST, Burkhalter R: The substance use profile of Canadian youth: exploring the prevalence of alcohol, drug and tobacco use by gender and grade. Addict Behav 2012, 37:318-322.

20. Leatherdale ST, Rynard V: A cross-sectional examination of modifiable risk factors for chronic disease among a nationally representative sample of youth: are Canadian students graduating high school with a failing grade for health? BMC Public Health 2013, 13:569. doi:10.1186/10.1186/ 1471-2458-13-569.

21. SAS Institute Inc: The SAS System for Windows: Version 9.3. Cary, NC: SAS Institute Inc; 2011

22. Government of Ontario: Smoke-Free Ontario Act. S.O. 1994, Chapter 10. http://www.e-laws.gov.on.ca/html/statutes/english/elaws_statutes_94t10_e htm\#BK18.

23. Kobus K: Peers and adolescent smoking. Addiction 2003, 98(Suppl. 1):37-55.

24. Tyas SL, Pederson LL: Psychosocial factors related to adolescent smoking: a critical review of the literature. Tob Control 1998, 7:409-420.

25. DiFranza JR, Coleman M: Sources of tobacco for youths in communities with strong enforcement of youth access laws. Tob Control 2001, 10:323-328.

26. Forster J, Chen V, Blaine T, Perry C, Toomey T: Social exchange of cigarettes by youth. Tob Control 2003, 12:148-154.

27. Alexander C, Piazza M, Mekos S, Valente T: Peers, schools, and adolescent cigarette smoking. J Adolesc Health 2001, 29:22-30.

28. Ennett ST, Flewelling RL, Lindrooth RC, Norton EC: School and neighborhood characteristics associated with school rates of alcohol, cigarette, and marijuana use. J Health Soc Behav 1997, 38(1):55-71.

29. Doubeni CA, Li W, Fouayzi H, DiFranza JR: Perceived accessibility as a predictor of youth smoking. Ann Fam Med 2008, 6:323-330. doi:10.1370/ afm.841.

30. Go M-H, Green HD Jr, Kennedy DP, Pollard M, Tucker JS: Peer influence and selection effects on adolescent smoking. Drug Alcohol Depend 2010, 109:239-242.

31. Hoffman BR, Monge PR, Chou C-P, Valente TW: Perceived peer influence and peer selection on adolescent smoking. Addict Behav 2007, $32: 1546-1554$

32. Øverland S, Aarø LE, Lindbak RL: Associations between schools' tobacco restrictions and adolescents' use of tobacco. Health Educ Res 2010, 25(5):748-756.

33. Pierce JP, Choi WS, Gilpin EA, Farkas AJ, Merritt RK: Validation of susceptibility as a predictor of which adolescents take up smoking in the United States. Health Psychol 1996, 15(5):355-361.

34. Fendrich M, Mackesy-Amiti ME, Johnson TP, Hubbell A, Wislar JS: Tobacco-reporting validity in an epidemiological drug-use survey. Addict Behav 2005, 30:175-181.

doi:10.1186/1617-9625-12-8

Cite this article as: Cole and Leatherdale: The association between senior student tobacco use rate at school and alternative tobacco product use among junior students in Canadian secondary schools. Tobacco Induced Diseases 2014 12:8.

\section{Submit your next manuscript to BioMed Central and take full advantage of:}

- Convenient online submission

- Thorough peer review

- No space constraints or color figure charges

- Immediate publication on acceptance

- Inclusion in PubMed, CAS, Scopus and Google Scholar

- Research which is freely available for redistribution 